\title{
Feeding ecology of the green sea turtle (Chelonia mydas) in the Galapagos Islands- CORRIGENDUM
}

\author{
J. CARRIÓN-CORTEZ, P. ZÁRATE AND J.A. SEMINOFF
}

doi:10.1017/So025315410000226, Published by Cambridge University Press, 16 April 2008.

An incorrect symbol in an equation in the Materials and Methods section as well as two incorrect words were written in the Acknowledgments section of the paper by Carrión-Cortez et al., 2010, first published online 16 April 2010 [1]. The authors apologies for these errors.

MATERIALS AND METHODS

The correct equation is as follows:

$$
\mathrm{Rw}=\frac{\mathrm{Q}\left(\mathrm{V}^{2}+\mathrm{FO}^{2}\right)^{1 / 2}}{\sum \mathrm{Q}\left(\mathrm{V}^{2}+\mathrm{FO}^{2}\right)^{1 / 2}} \times 100
$$

\section{ACKNOWLEDGEMENTS}

Paragraph 1, line 7; the correct name is Peter Dutton instead of Peter Dunn.

Paragraph 1, line 16; the correct is La Jolla instead La Julla.

REFERENCE

1. Carrión - Cortez J.A., Zárate P. and Seminoff J.A. (2010) Feeding ecology of the green sea turtle (Chelonia mydas) in the Galapagos Islands. Journal of the Marine Biological Association of the UK published by Cambridge University Press 16 April 2010. doi:10.1017/So025315410000226 